lessons can be learnt by studying evidence for Holocene sea level and ice sheet change in the context of regional climate change, such as the Medieval Warm Period and the Little Ice Age (see Kelly and Long, and Yu et al., this issue). In turn, Holocene changes must be considered in the light of the large changes in ice volume and sea level during the termination of the last glacial period (T1). During T1, the interaction between ice sheets, ocean circulation and global warming greatly perturbed the ice sheets and can be regarded as a case study for large changes in global climate on decadal to centennial timescales (see PALSEA, 2009). In particular, relative sea level variations during this period may help reveal which ice sheets collapsed in response to climate change during $\mathrm{T} 1$ (see Milne, this issue). Other periods in the past also have lessons for millennial-scale climate variability (see Gonzalez and Dupont, this issue).

Paleodata can help constrain the sensitivity of ice volume and sea level change to broader climate change. It can help place limits on future rates of change and it can give a multi-decadal and multi-centennial context to sea level and ice sheet change. The contributions in this edition of PAGES news will give recent examples of this work.

\section{Note}

For more information on the PALSEA Working Group please visit www.climate.unibe. ch/ siddall/working_group.html

\section{References}

Alley, R.B., Clark, P.U., Huybrechts, P. and Joughin, I., 2005: Ice-sheet and sea-level changes, Science, 310: 456-460.

Fleming, K., Johnston, P., Zwartz, D., Yokoyama, Y., Lambeck, K. and Chappell, J., 1998: Refining the eustatic sea-level curve since the Last Glacial Maximum using far- and intermediate-field sites, Earth and Planetary Science Letters, 163(1-4): 327-342. DOl:10.1016/S0012-821X(98)00198-8 ().

Gregory, J.M., Lowe, J.A. and Tett, S.B.T., 2006: Simulated global-mean sea-level changes over the last half-millennium, Journal of Climatology, 19(18): 4576-4591.

IPCC, 2007: Summary for Policymakers. In: Solomon, S. et al., (Eds), Climate Change 2007: The Physical Science Basis. Contribution of Working Group I to the Fourth Assessment Report of the Intergovernmental Panel on Climate Change, Cambridge University Press, Cambridge, United Kingdom and New York, USA.

PALSEA, 2009: The sea-level conundrum - case studies from paleoarchives, Journal of Quaternary Science, in press.

\title{
Recent Antarctic and Greenland ice-mass fluxes from satellite observations and their significance
}

JONATHAN BAmBER

Bristol Glaciology Centre, School of Geographical Sciences, University of Bristol, UK; j.bamber@bristol.ac.uk

\section{Understanding contemporary ice sheet behavior is crucial for estimating future trends but the useful satellite observation period of $\sim 20$ years is too short. Paleodata, especially from the Holocene, have the potential to help us interpret the contemporary observations.}

Reliable, large-scale observations of the mass trends of the ice sheets do not extend very far back in time. The earliest data set covering the whole of Greenland and $80 \%$ of Antarctica began with the launch of ERS-1 in 1991. Since then, other satellites and sensors have provided unique insights into the time-evolving behavior of the ice sheets. Two pressing issues emerge from these observations. The first is the lack of consistency between estimates of the mass balance (Fig. 1), and the second is whether the large and rapid fluctuations in ice dynamics observed are a secular response (i.e., a one-way trend) to external forcing or just part of the "normal" variability in flow that is constantly taking place. Considerable weight and importance has been placed on the apparent increasing mass loss from both Greenland and West Antarctica over the last decade (e.g., Fig. 1). The implication is that this trend is a secular response to external forcing (Hansen, 2007) but the record is too short to confirm this with any certainty. Resolving this issue is crucial, and this is where the paleo record of ice sheet variability, particularly during the Holocene, could, and perhaps must, provide some of the answers.

Since the mid 1990s, our view of ice sheet dynamics has undergone a profound paradigm shift (Bamber et al., 2007). The conventional wisdom was that

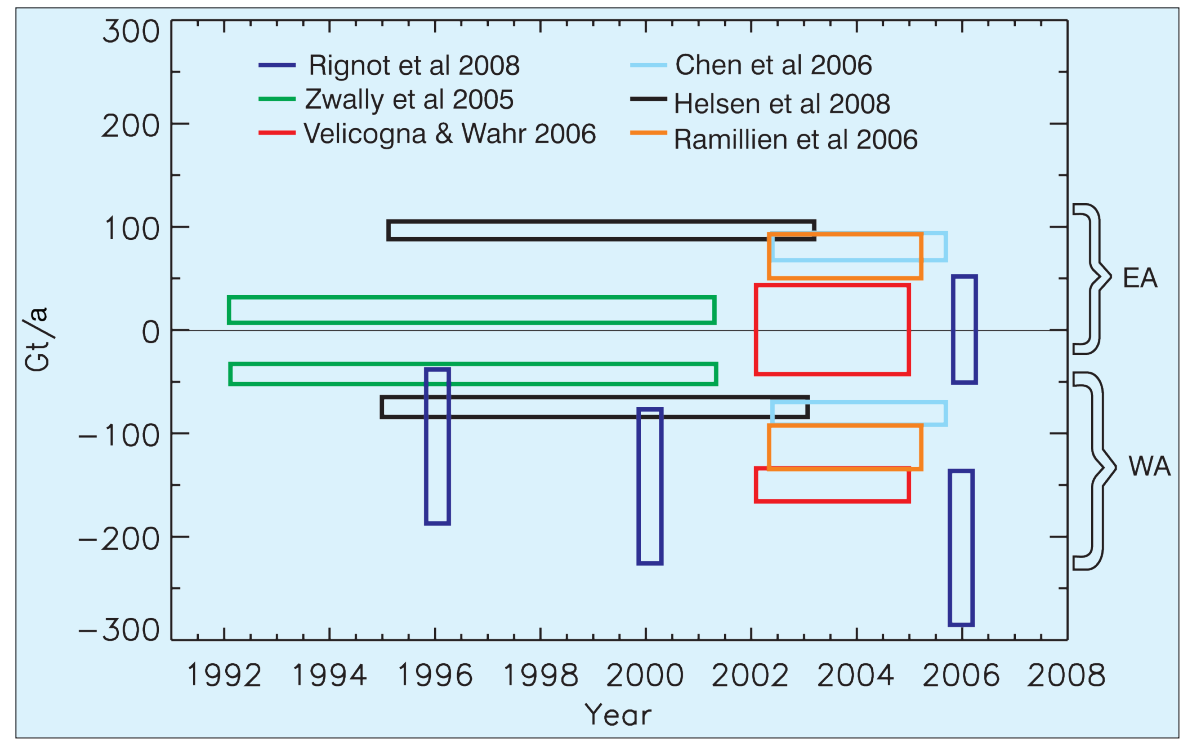

Figure 1: Estimates of the mass balance of the West (WA) and East (EA) Antarctic ice sheets (gigatonnes per year, Gt/a) from a variety of observations and authors. The width of the bars indicates the time period for the estimate and the thickness represents the uncertainty. Zwally et al., (2005) is estimated from satellite radar altimetry. Helsen et al., (2008) is a reassessment of radar altimetry data using a firn compaction model driven by climate model data. (Rignot et al.,, 2008) is from mass budget estimates combining velocity and thickness data with modeled snowfall. Chen et al., 2006, Ramillien et al., 2006, Velicogna and Wahr, 2006 are from gravity measurements from GRACE (Gravity Recovery and Climate Experiment).

the response time of ice sheet dynamics was on the order of $10^{3}-10^{4}$ years. The numerical ice sheet models developed during the 1980s supported this "wisdom" (Huybrechts and de Wolde, 1999). These models operated at relatively course resolution, typically $40 \mathrm{~km}$, with certain simplifications to the physics employed that were considered reasonable at the continental scale. As a consequence, the models were not able to resolve individual ice streams (Fig. 2). During the last decade, with the advent of satellite-based repeat pass synthetic aperture radar interferometry (InSAR), a radically different view has emerged. For example, between 1997 and 2000, the largest outlet glacier (by discharge volume) in Greenland, Jakobshavn 


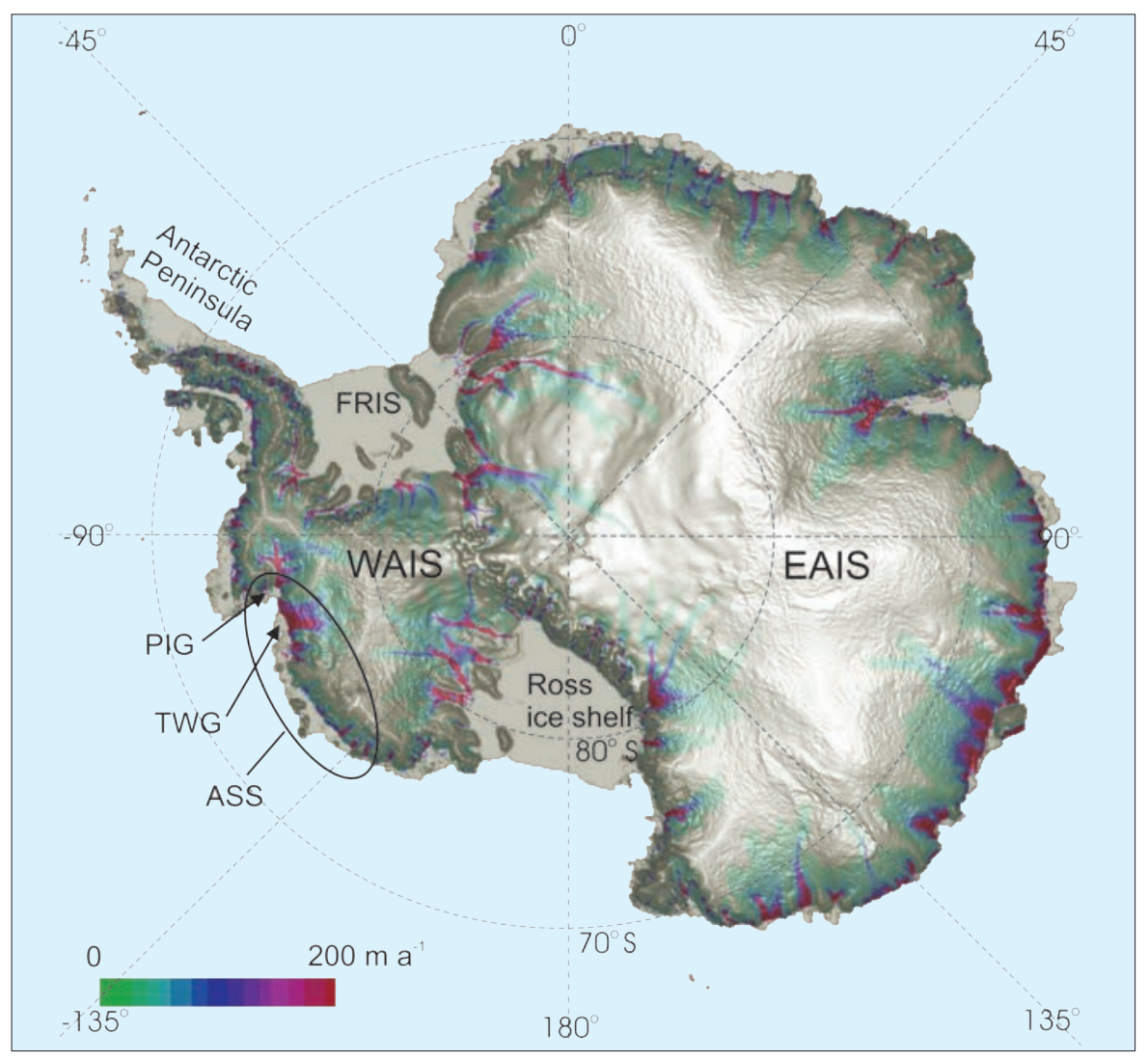

Figure 2: Surface topography (gray) and surface-ice velocities ( $\mathrm{m} / \mathrm{a}$ ) (colored) for the West (WAIS) and East (EAIS) Antarctic Ice Sheet, indicating the locations of the ice streams and outlet glaciers along the margins of the ice sheet. Pine Island Glacier (PIG) and Thwaites Glacier (TWG) are responsible for the majority of the mass loss in the Amundsen Sea Sector (ASS) of West Antarctica (Rignot and others, 2008). Also shown are the Ross and Filchner Ronne lce Shelves (FRIS)

Isbrae, doubled in velocity from around 6 $\mathrm{km} / \mathrm{a}$ to $12 \mathrm{~km} / \mathrm{a}$ (Joughin et al., 2004) (Fig. 3). Interestingly, similar observations, for a slightly different time period, showed the same rapid, simultaneous speed-up of two glaciers on the southeast coast of Greenland (Luckman et al., 2006). Smaller, but still substantial, speed-ups have also been observed for ice streams draining the West Antarctic Ice Sheet (WAIS) (Fig. 2). Some of these, in particular Pine Island Glacier (Fig. 1), have continued their acceleration, resulting in an increasingly negative mass balance since 1996 (Rignot et al., 2008).

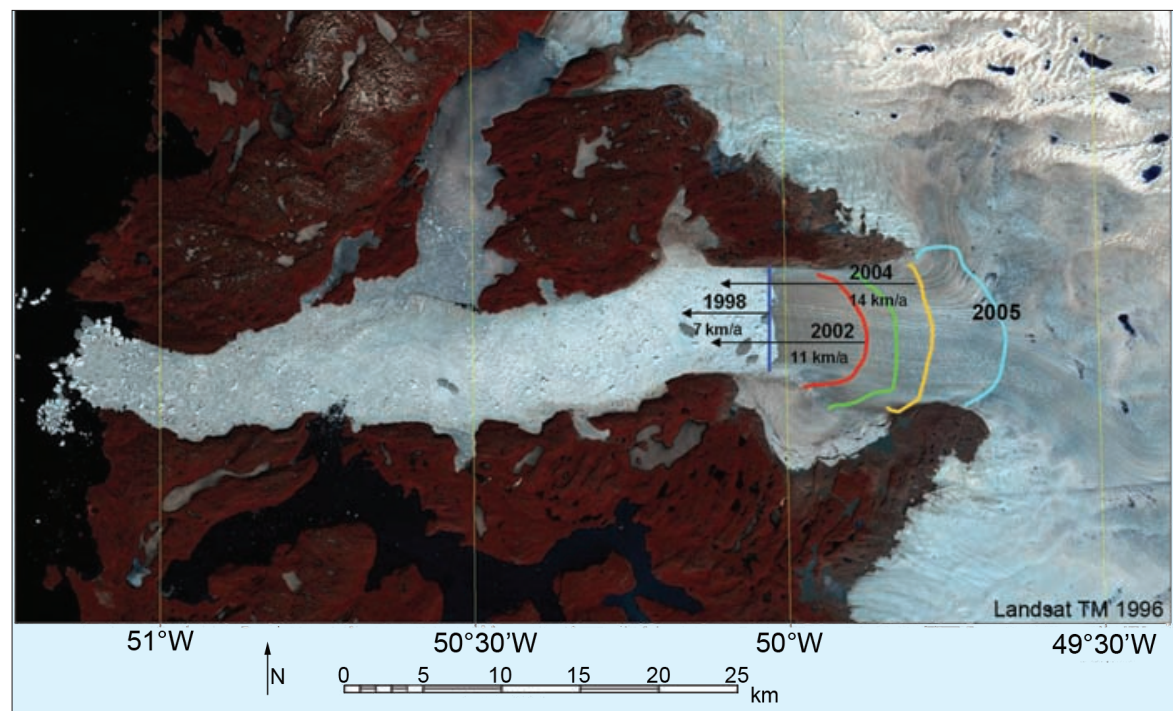

Figure 3: Landsat TM image of Jakabshavn Isbrae from 1996 showing the floating tongue and calving positions and velocities at various dates during the period of speed-up of the glacier, which is the largest (by discharge volume) in Greenland (Joughin et al., 2004). Figure courtesy K. Steffen.

Thus, although there is a lack of consensus about the absolute value for the mass balance of the ice sheets, there is agreem Shepherd and Wingham, 2007).

It has become clear over the last decade that parts of the ice sheets can rethere is variability in flow over a range however, is whether the recent observations of rapid and large changes in motion are in any way unusual. Do they represent a secular trend in response to atmospheric and/or oceanic warming, as some have implied (Hansen, 2007), or is this simply normal ice sheet variability on a decadal timescale? The answer to this question is fundamental to i) our understanding of ice sheet behavior, ii) interpretation of the short, satellite-derived mass trends, and iii) predicting future ice sheet behavior. It would be fortuitous that we started our measurements at just the right time to observe the start of a secular, monotonic trend. On the other hand, it is noteworthy that similar trends are seen for both Greenland and the WAIS, and that they are not restricted to single drainage basins but appear to have a common forcing. It is important to note, however, that the ice sheets are also still likely to be responding to changes in forcing at the end of the last glacial around 12 ka BP. As a consequence, they will be out of equilibrium with respect to the modern-day climate, and their reaction to external forcing is an integrated response to changes over multiple millennia.

A reasonable contention would be that the resolution of this question is well suited to a numerical modeling experiment. The models are, however, currently playing "catch up" with the observations. Considerable effort is being invested in the development of higher-order models that contain a more detailed representation of the physical processes that are now believed to be important for reproducing the observed behavior (Pattyn, 2003). There are, however, other issues that may render this problem difficult for numerical models to address in the medium term. In particular, the basal boundary conditions are an important constraint for the models but are poorly known. Geothermal heat flux, for example, may vary by a factor of twenty across Greenland and Antarctica (Fahnestock et al., 2001), yet the models generally assume a global mean value. Ice has an anisotropic rheology (i.e., its flow properties vary with direction) and can be a factor of ten weaker in one plane as opposed to another but, again, the models currently cannot deal with this. Further, for large swathes of East Antarctica there are no direct observations of ice thickness; a critical boundary condition for numerical modeling, as ice velocity is proportional to the fourth power of thickness.

The question then is can paleodata capture past variability in dynamics and ice sheet extent with sufficient fidelity to be able to address the pressing and important questions that have emerged from the contemporary record? Pilot stud- 
ies are beginning to address aspects of this. For example, there is intriguing evidence based on historical aerial photography from the $20^{\text {th }}$ century, in addition to dating of lateral moraines and trimlines, that the Jakobshavn Isbrae catchment (Fig. 3) has fluctuated in volume several times since the Little Ice Age (Csatho et al., 2008). Yet we do not know whether, or what, contemporaneous external forcing was responsible for these changes. Nonetheless, this study does suggest that the contemporary observations, for this ba$\sin$ at least, are not atypical. The work has also shown that it is possible to produce (some of) the data we need to help place the modern observations in a longer-term context. There are currently no equivalent studies for WAIS catchments or on a larger scale in Greenland. In fact, even the gross deglacial evolution of the WAIS is poorly known (Ackert et al., 2007). Let's hope this changes soon!

\section{References}

Bamber, J.L., Alley R.B. and Joughin I., 2007: Rapid response of modern day ice sheets to external forcing, Earth and Planatary Science Letters, 257: 1-13.

Bindschadler, R., 2006: The environment and evolution of the West Antarctic ice sheet: setting the stage, Philosophical Transactions of the Royal Society A: Mathematical Physical and Engineering Sciences, 364(1844): 1583-1605.
Huybrechts, P. and de Wolde, J., 1999: The dynamic response of the Greenland and Antarctic ice sheets to multiple-century climatic warming, Journal of Climate, 12(8): 2169-2188.

Joughin, I., Abdalati W. and Fahnestock, M., 2004: Large fluctuations in speed on Greenland's Jakobshavn Isbrae glacier, Nature, 432(7017): 608-610.

Shepherd, A. and Wingham, D., 2007: Recent sea-level contributions of the Antarctic and Greenland ice sheets, Science, 315(5818): 1529-1532.

For full references please consult:

www.pages-igbp.org/products/newsletters/ref2009_2.html

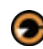

\title{
U-series dating of fossil coral reefs: Consensus and
}

\section{controversy}

\author{
Morten B. Andersen ${ }^{1}$, C.D. Gallup² ${ }^{2}$ D. Scholz ${ }^{3}$, C.H. Stirling ${ }^{4}$ and W.G. Thompson ${ }^{5}$ \\ 'Department of Earth Sciences, University of Bristol, UK; ${ }^{2}$ Department of Geological Sciences, University of Minnesota Duluth, USA; ${ }^{3}$ School of \\ Geographical Sciences, University of Bristol, UK; ${ }^{4}$ Department of Chemistry, University of Otago, New Zealand; ${ }^{5}$ Department of Geology and \\ Geophysics, Woods Hole Oceanographic Institution, USA; wthompson@whoi.edu
}

\section{New developments in U-series coral dating are sparking a healthy debate over how best to interpret coral ages from older fossil coral reefs, reinvigorating research in sea level changes during previous interglacial periods, and fostering a new appreciation of the challenges ahead.}

Understanding potential magnitudes and rates of future sea level change is an urgent societal and scientific problem. The history of sea level change provides crucial information about the links between climate forcing, response, and sea level change; as well as critical constraints on future sea level rise. The most direct method for reconstructing sea level history is uranium/thorium (U/Th) dating of fossil corals that once grew near the sea surface. This method has the potential to provide a detailed and well-dated record of sea level change for the last 700 ka. Given the relatively continuous growth of coral reefs in tropical seas and the precision of U-Th dating, the construction of a detailed and accurate sea level history should be a straightforward task. Despite decades of effort, this crucial goal remains elusive because many $\mathrm{U} / \mathrm{Th}$ ages are unreliable due to mobility of the relevant isotopes, a problem that worsens with increasing coral age. Recently, sea level research has been reinvigorated by new insight into the mechanisms of U-series isotope mobility in fossil corals and by significant improvements in analytical techniques.

\section{Identifying reliable coral ages}

Recent advances in analytical techniques have improved the precision of U/Th dating, extending the dating range to at least 700 ka (see Stirling and Andersen, this issue). Unfortunately, analytical challenges are not the only hurdle to be overcome in the pursuit of accurate U/Th coral ages. Isotope mobility often invalidates the "closed-system" assumption that is fundamental to radiometric dating techniques. Corals can either gain or lose uranium and thorium, changing the apparent age. Furthermore, many corals seem to be subject to a coupled loss or gain of ${ }^{234} \mathrm{U}$ and ${ }^{230} \mathrm{Th}$ isotopes (Fig. 1). The best explanation for this systematic addition appears to be the coupled addition of ${ }^{234} \mathrm{Th}$ (which rapidly decays to ${ }^{234} \mathrm{U}$ ) and ${ }^{230} \mathrm{Th}$ that is produced by the decay of ${ }^{238} \mathrm{U}$ and ${ }^{234} \mathrm{U}$ in the surrounding carbonate matrix. This effect results in a bias toward erroneously older apparent ages. These "open-system" artifacts represent a key challenge in translating $\mathrm{U} / \mathrm{Th}$ isotope ratio measurements into reliable coral ages. Two general strategies are employed to reduce the impact of these artifacts. The "screening" approach focuses on identifying closed-system corals using criteria such as initial ${ }^{234} \mathrm{U} /{ }^{238} \mathrm{U}$ and the ${ }^{231} \mathrm{~Pa} /{ }^{235} \mathrm{U}$ chronometer (e.g., Gallup et al., 1994), while the "correction" approach attempts to correct ages for opensystem effects (e.g., Thompson et al., 2003; Villemant and Feuillet, 2003; Potter et al., 2004; Scholz et al., 2004).

\section{Seawater ${ }^{234} U /{ }^{238} U$}

Both screening and correction approaches in U-series coral dating make an assumption about the initial ${ }^{234} \mathrm{U} / 238 \mathrm{U}$ of the coral, which is most often assumed to be similar to that of modern seawater. The validity of this assumption has some support from modeling of ocean ${ }^{234} \mathrm{U}$ residence times (Richter and Turekian, 1993), and data from aragonitic sediments suggest little evidence of a large long-term change over the last 800 ka (Henderson, 2002). In contrast, there is convincing evidence from initial ${ }^{234} U /{ }^{238} \mathrm{U}$ in corals that ocean ${ }^{234} \mathrm{U} /{ }^{238} \mathrm{U}$ was as much as $7 \%$ o lower during the last glacial period (e.g., Hughen et al., 2004). Although corals are not ideal archives of ocean ${ }^{234} \mathrm{U} / 238 \mathrm{U}$ because of open-system effects, information about past seawater ${ }^{234} \mathrm{U} /{ }^{238} \mathrm{U}$ may be gleaned from an isotope ratio diagram. The dominant trend, lying for the most part above the closed-system curve (Fig. 1), suggests that most corals appear to have gained both ${ }^{234} \mathrm{U}$ and ${ }^{230} \mathrm{Th}$, although the possibility of ${ }^{234} \mathrm{U}$ and ${ }^{230} \mathrm{Th}$ loss cannot be rigorously ruled out. Thus, the lower bounds of the data array may indicate the unaltered compositions defining seawater ${ }^{234} \mathrm{U} /{ }^{238} \mathrm{U}$ for a specific time period (e.g., Andersen et al., 2008), regardless of the specific alteration mechanism. For coral dating, any difference between the assumed and actual initial ${ }^{234} \mathrm{U} /{ }^{238} \mathrm{U}$ will produce a systematic offset from the true age for corals selected as "reliable" using screening criteria, and a similar offset for ages calculated using a correction approach. The sensitivity of ages to assumptions about initial ${ }^{234} \mathrm{U} /{ }^{238} \mathrm{U}$ can be directly 